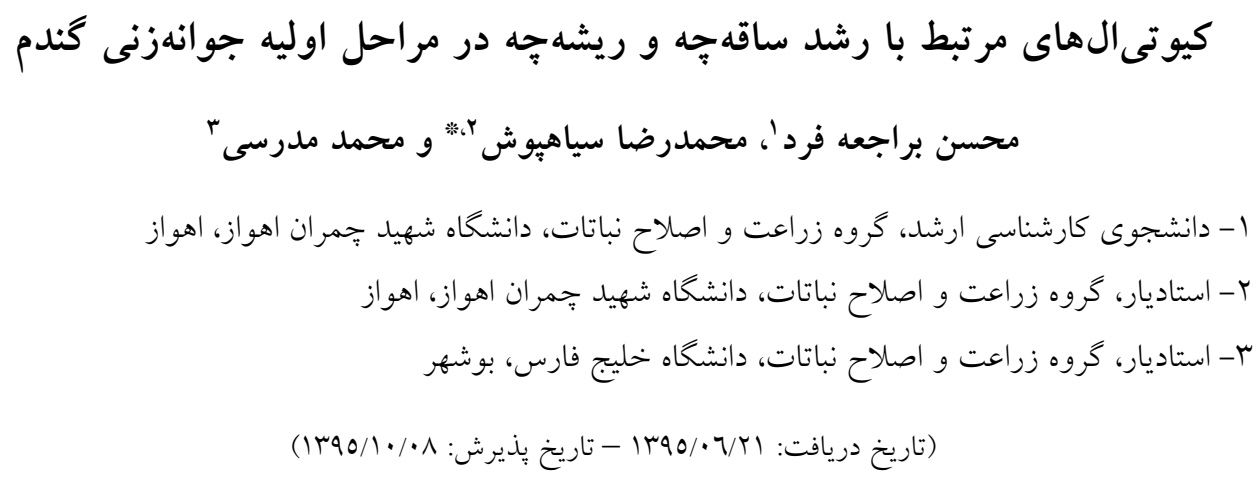

حكيده

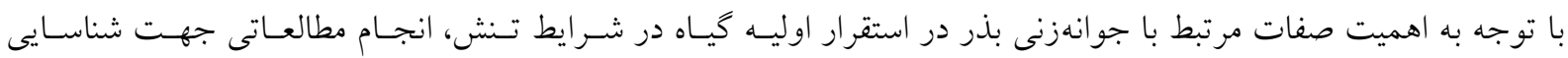

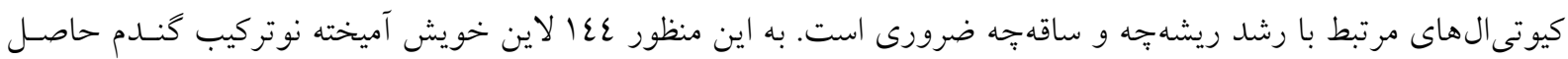

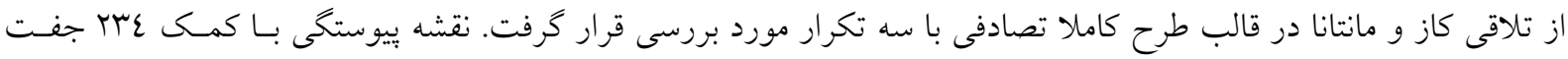

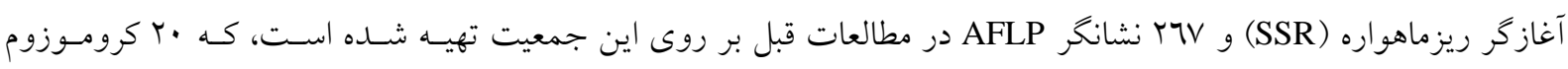

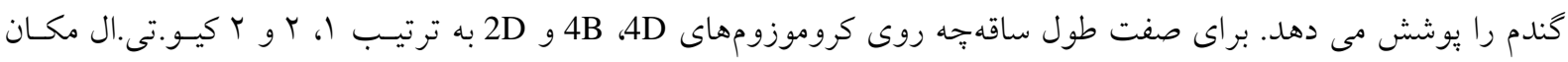

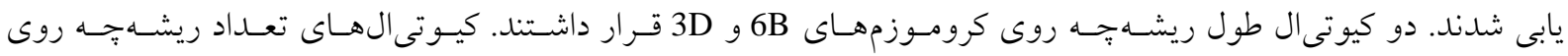
كروموزومهاى 4A، 5A و 3B شناسايى شدند. براى هر كدام از صفات وزن خشك ساقهجه و وزن خشك ريشهجه به ترتيـب

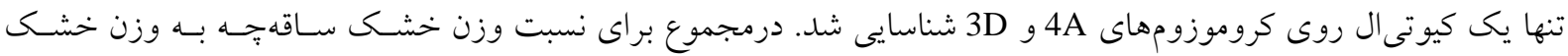

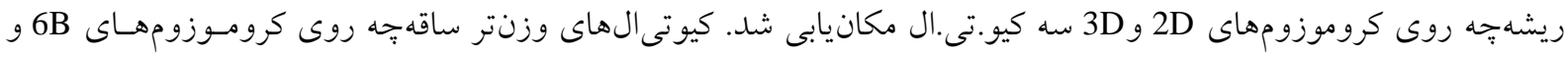

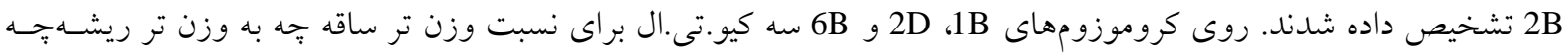

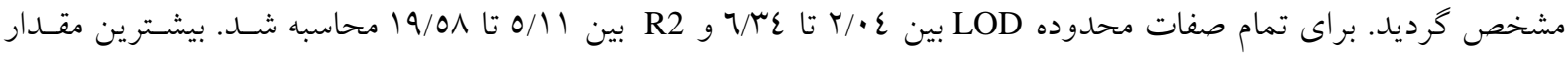

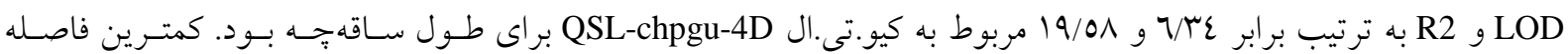

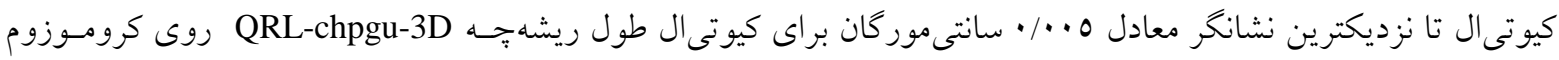
3D در مجاورت نشانكر AFgcCGb بدست آمد. وازَّان كليدى: ساقهجه، كيوتىال، كياهجه، كُندم، ريشه 
به وزن خشى ريشه هـ نيز يك كيوتىال روى كروموزوم

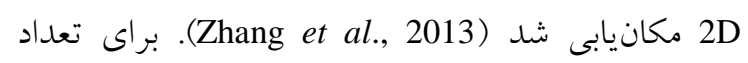

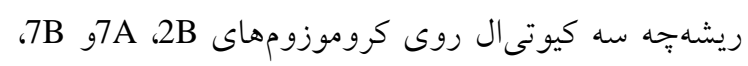

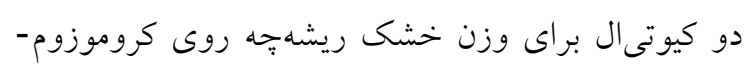

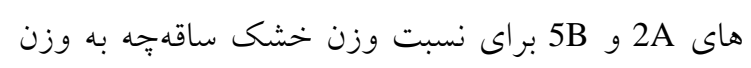

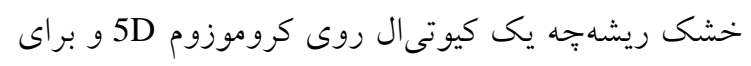

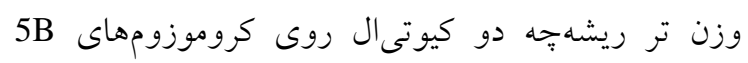

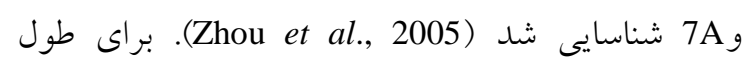

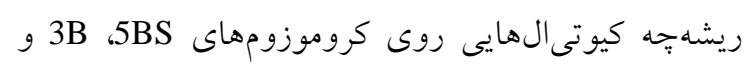

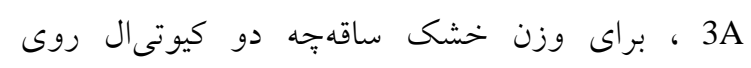

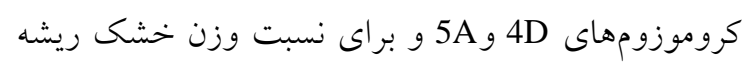

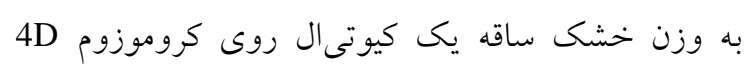

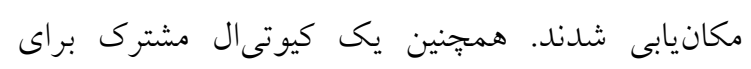

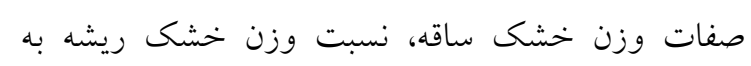
ساقه، ارتفاع و وزن هزار دانه، روى كروموزوم 4D مكان

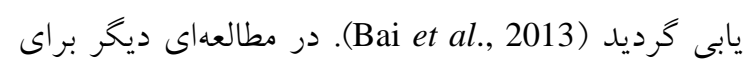
تعداد ريشهجه يك كيوتى ال روى كروموزوم 2BL، برديد (B.

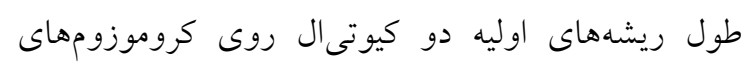

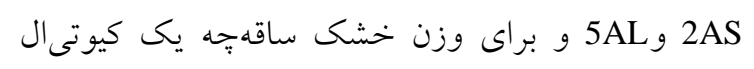
Sanguinet et al., ) روى كروموزوم 1BL مكانيابى شئ وند 2007). براى طول ريشه يك كيوتى ال روز كوم كروموزوم

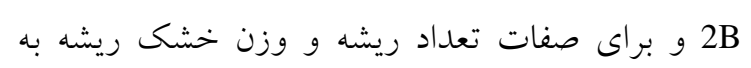

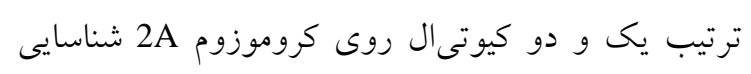

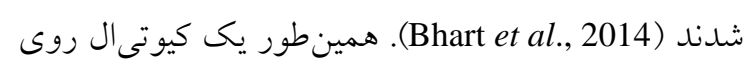
كروموزوم 5A براى طول ريشهاى اوليه يافت شده است

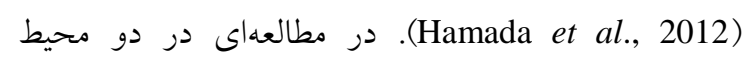

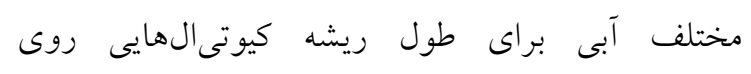

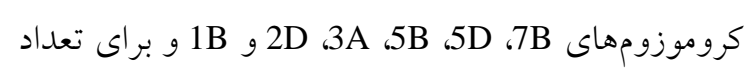

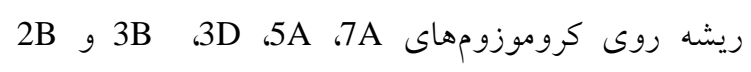
مشخص شد (Liu et al., 2013). يك كيوتىال در شرايط

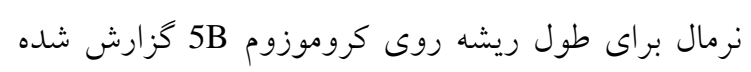
است (Landjeva et al., 2008). با توجه به اهميت صفات مرتبط با جوانهزنى بذر در

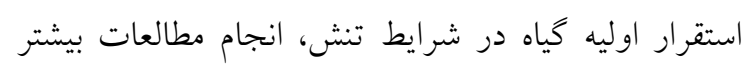

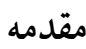

كُندم (Triticum aestivum L.) مهمترين كياه زراعى است كه در نقاط مختلف جهان كشت و كار مىشود ( Gupta

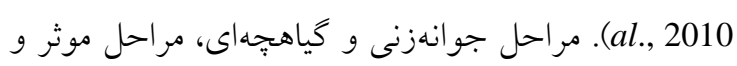

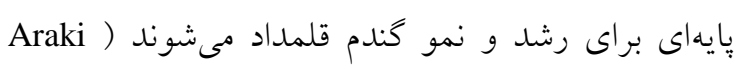
and Iijima, 2001

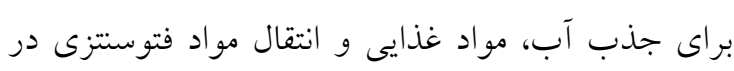

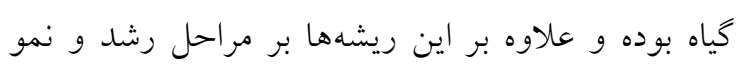

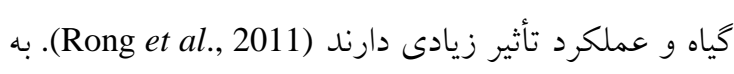
احتمال فراوان ريشههاى اوليه بيش از ريشههاى ثانويه بر دان عملكرد تأثير مى كذارند (Manske and Vlek, 2002). بسيارى از محققين بر اين عقيده هستند كه سيستم ريشه-

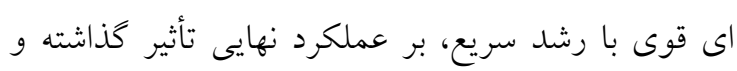

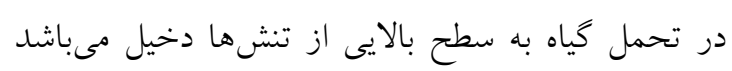

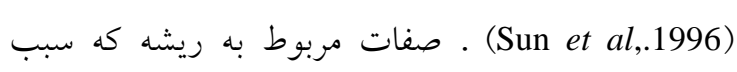
بهبود افزايش توانايى جذب آب و مواد غذايى در كياه

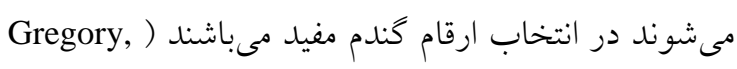

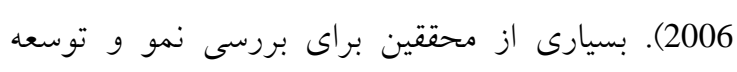

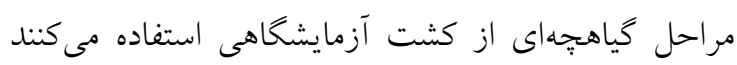
(Yang et al., 2010; Zhu et al., 2005) تجزيه كيوتى ال براى صفات مربوط به ريشه توجه زيادى

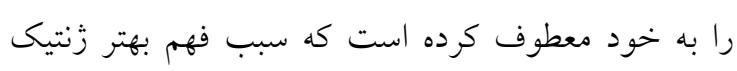

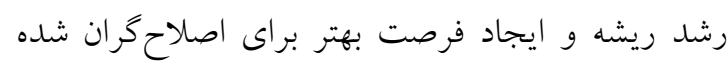

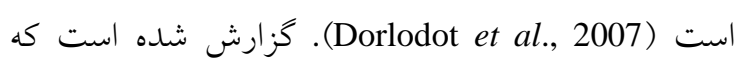
رشد ريشه توسط زنهاى زيادى با اثرات كم كنترل مى -

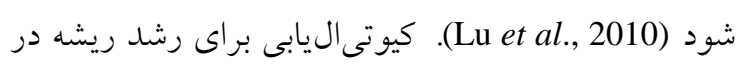
بيشتر كياهان از جمله كندم كزارش شده است (Lhang et Sal., 2013

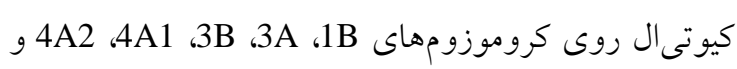
Christopher et al., ) شناسايى و كزارش شند كروز

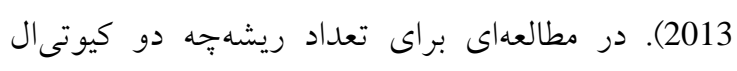
روى كروموزوم 4D، براى صفت وزن خشك ساقه كندم

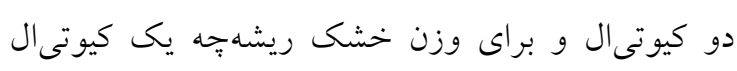

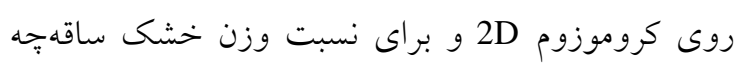


شمارش گرديد و سِس ميانگين ·ل بوته براى تجزيه كيوتىال مورد استفاده قرار گرفت. براى اندازهگيرى طول ساقهجه و طول ريشهجه از خطكش ميليمترى استفاده شد. همجنين براى وزن خشى ريشهجه و وزن خشك ساقهجه، بعد از جدا كردن ريشهجه و ساقهجه از كَياهجه

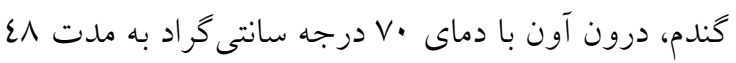
ساعت قرار داده شدند. براى توزين ساقهجه و ريشهجه از ترازوى دقيق (با دو رقم اعشار) استفاده گرديد.

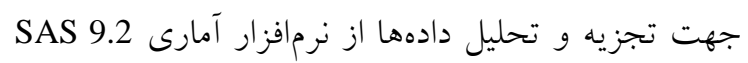
استفاده شد. قبل از انجام تجزيه واريانس دو فرض اصلى لهيل تجزيه واريانس شامل نرمال بودن توزيع اشتباهات

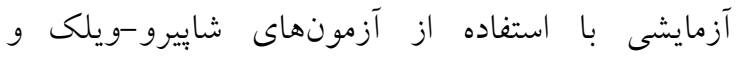
كلموكروف-اسميرنوف و يكنواخت بودن واريانس خطاهاى آزمايشى با استفاده از آزمون بارتلت مورد بررسى قرار گرفت. مكان يابى كيوتىال به وسيله برنامه Windows QTL cartographer 2.5 (Wang et al., 2005 و بر اساس مكانيابى فاصلهاى مركب انجام شد. آستانه LOD =2، حداقل فاصله يويش زنوم r سانتى

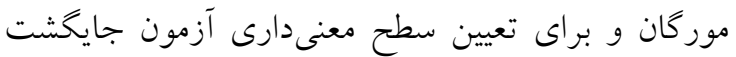

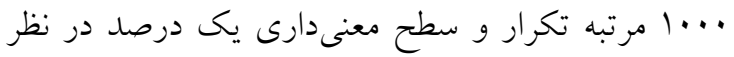
Mرفته شد. از نرم افزار براى ترسيم جايخاه كيوتى الها روى كروموزومها استفاده كرديد.

\section{نتايج و بحث}

نتايج تجزيه واريانس نشاندهنده وجود اختلاف معنىدار

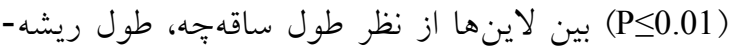
קֶه، تعداد ريشه جِه، وزن تر ريشه جِه، وزن خشك ريشهجֶه، وزن خشك ساقهجه، نسبت وزن خشك ساقه وزن خشك ريشهجه، وزن تر ساقهجه و نسبت وزن تر ساقهجه به وزن تر ريشهجه بود (جدول ()). توزيع فنوتييى براى تمام صفات در شكل ا آورده شده است. نتايج نشان از وجود تفرق متجاوز Transgressive) segregation) بود. به اين شرح كه دامنه تغييرات فنوتييى براى طول

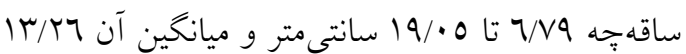

جهت شناسايى كيوتى الهاى مرتبط با رشد ريشهجه و ساقهجه ضرورى است. به اين منظور آزمايش حاضر با بالِ هدف تعيين مكانهاى زنى كنترل كننده صفات مرتبط با باتين

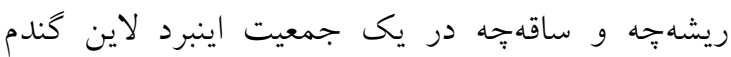
توليد شده جهت انجام مطالعات تنش گرما طراحى و اجرا كرديد.

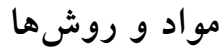

در اين آزمايش عـا رگه درونزاد نوتركيب F9 حاصل از تلاقى ارقام كاز (Jupatco F73/Blue Jay/Urest T81) و مانتنا (PI372129/2*Pondera) مورد استفاده قرار گرفتند. رقم كاز در مركز بين المللى سيميت آزاد شده و متحمل به گرما است در حالى كه مانتنا رقم حساس به كرما مىباشد (Ibrahim and Quick., 2001). لاينهاى اينبرد مورد استفاده تا نسلF6 به روش نتاج تك بذر به دست

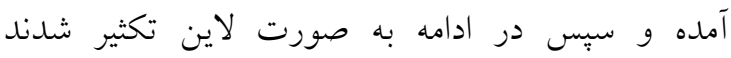
(Mohammadi et al., 2004) نقشه ويبوستكى با كمى عrr جفت آغازگر ريزماهواره و و (SSR) Modarresi, ) كروموزوم كندم را يوشش مى r.

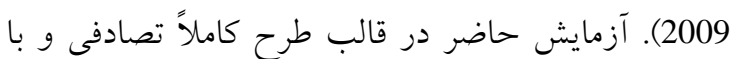
سه تكرار در آزمايشكاه زنتيك و اصلاح نباتات دانشكده دراح كشاورزى دانشگاه شهيد جمران اهواز در درون جعبههاى جوانهزنى اجرا كرديد. در هر تكرار براى هر لاين مورد بررسى •r علد بذر كشت گرديد. جهت ضدعفونى ابتدا بذور با آب معمولى و آب مقطر شتته و در مرحله بعد در محلول اتانول ·O درصد به مدت ·r ثانيه قرار داده شدند. سبس با آب مقطر شستشو شده و در هييوكلريد سديم ץ درصد به مدت نيم ساعت نخهلدارى و در نهايت با آب مقطر شستشو شدند. به منظور جلو گيرى از بروز

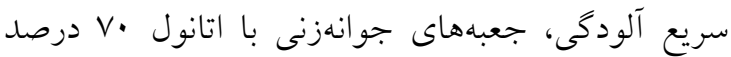
ضدعفونى و كاغذهاى صافى كه به عنوان بستر كشت انت

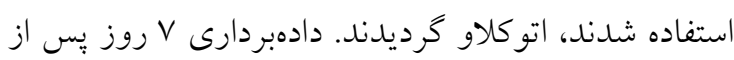

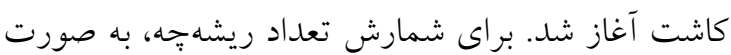

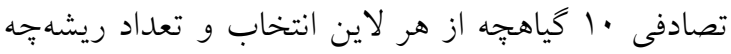



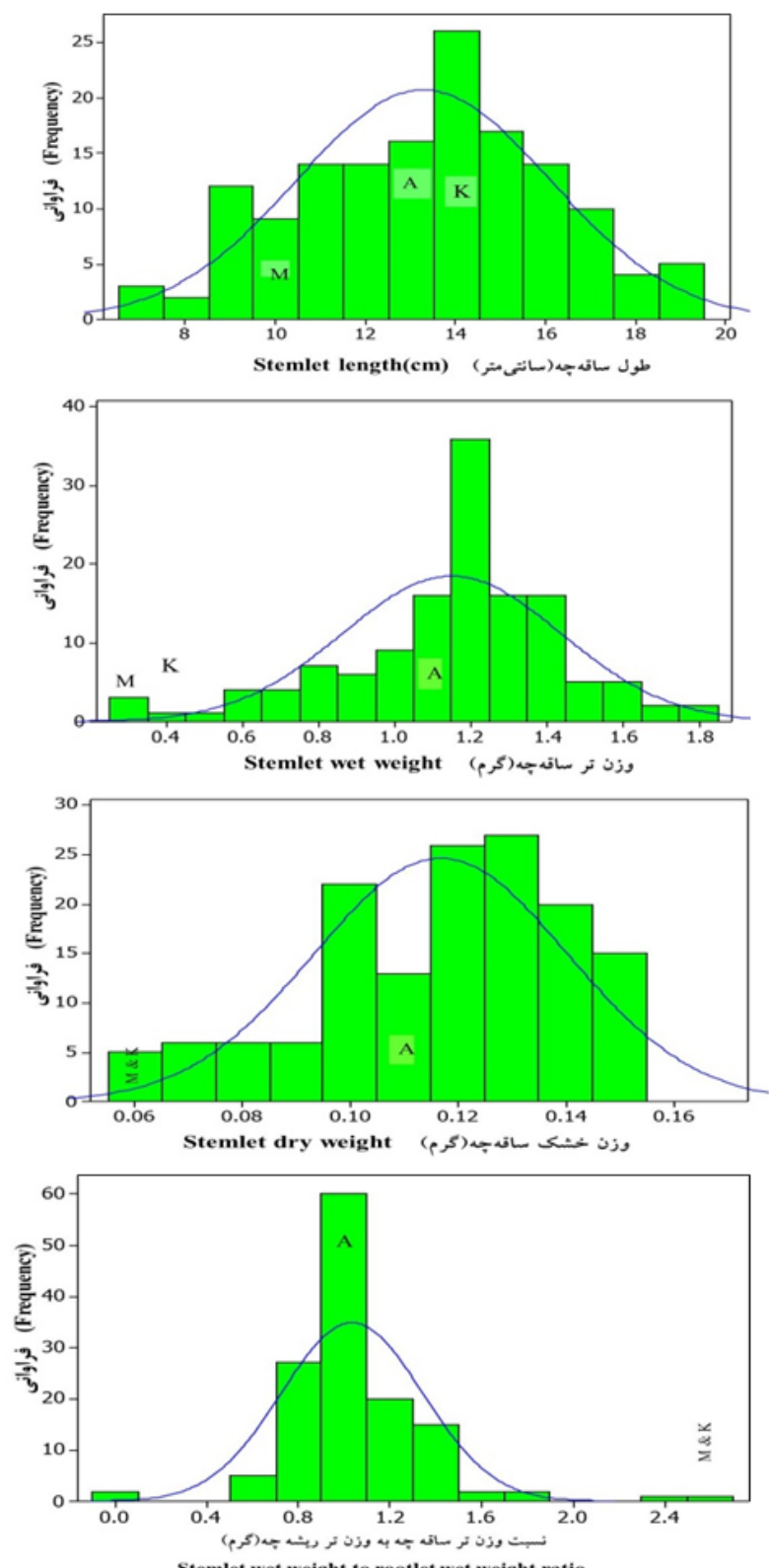

Stemlet wet weight to rootlet wet weight ratio
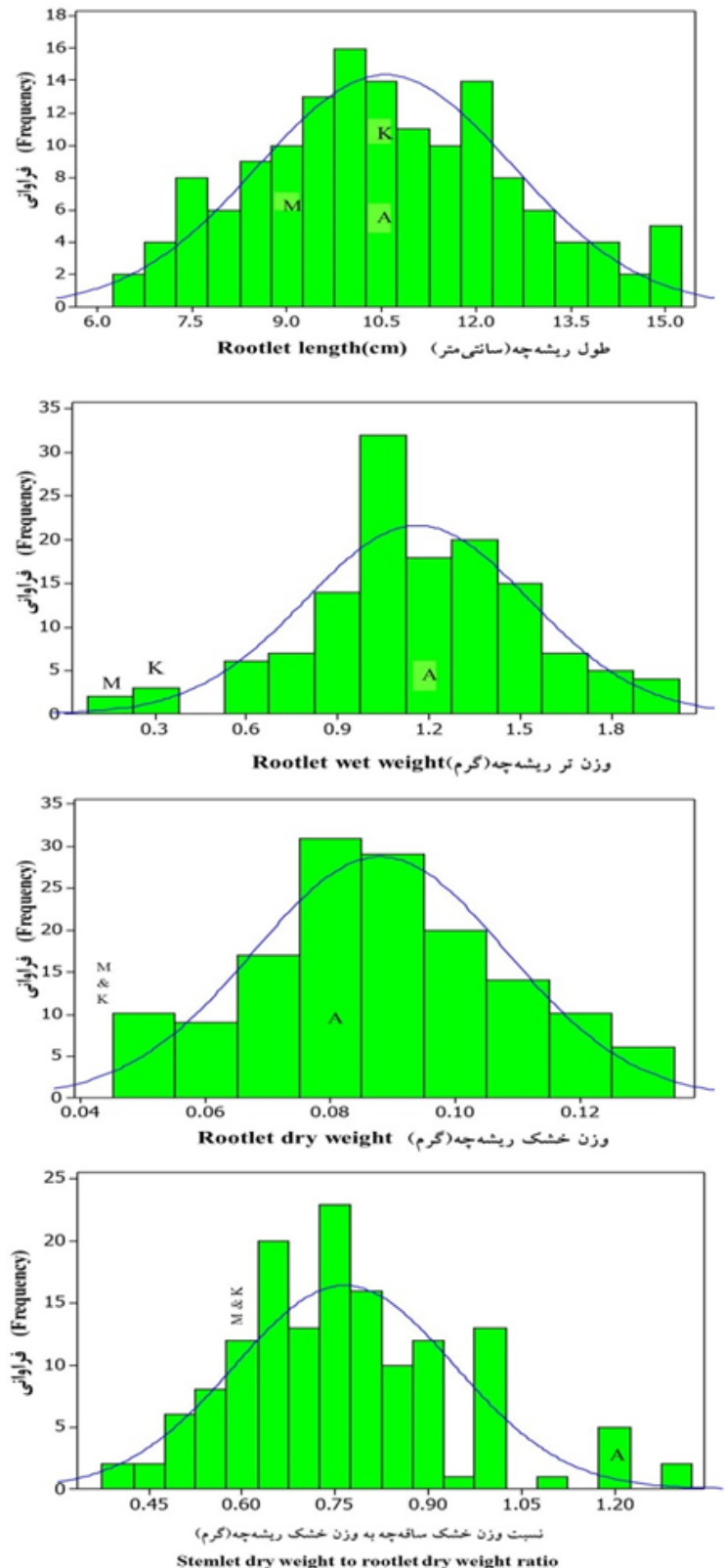

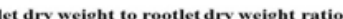

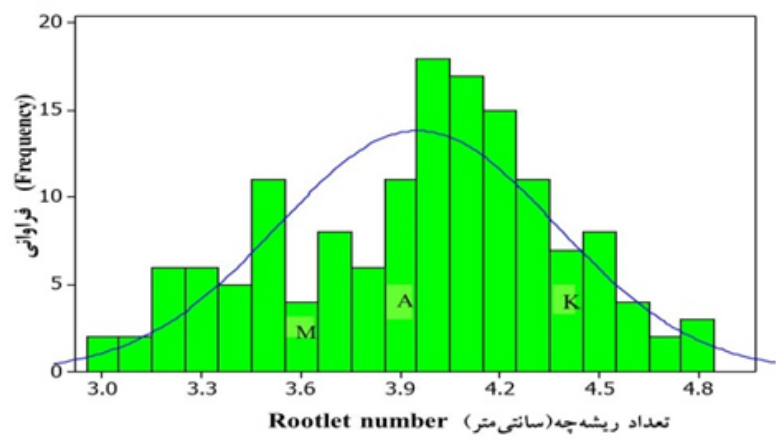

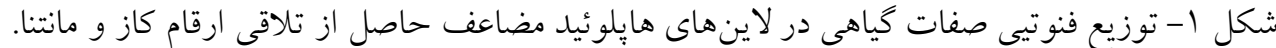

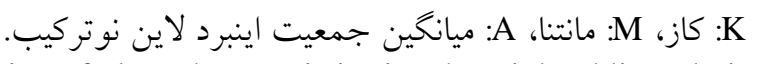

Figure 1. Phenotypic distribution of plant characteristics in wheat inbred lines derived from the Kaz and Mantna cross, K: Kaz mean, M: Mantna and A: Inbred line population mean. 
مشاهده شده ناشى از اثر افزايشى زنها در درون جمعيت مىباشد. براى وزن خشك ساقهجه نيز هر دو والد ميزان كمترى نسبت به افراد جمعيت را نشان دادند. تجزيه كيوتى ال: با توجه به اهميت صفات ريشه خصوصا در مراحل اوليه رشدى گياه و تأثير آن بر دوره زندگى و عملكرد، شناسايى مكانهاى زنومى حاوى زنهاى كنترل كننده اين صفات مىتوانند به صورت بسيار مؤثر در اصلاح گياهان براى افزايش عملكرد و تحمل به تنشها به كار كرفته شود. در اين مطالعه براى صفات تعداد

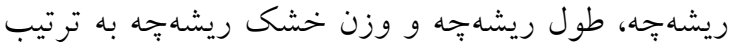
ع، ب و ا كيوتى ال روى كروموزومهاى 6B، 3D، 3B،

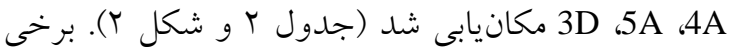
كيوتى الهاى بدست آمده براى صفات ريشه بهه و ساقهجه. بر روى يك كروموزوم بودند كه اين امر احتمالا به دليل Poorsahrigh et al., ) بيوستخى زنتيكى زنها مىباشد QRDW- و QLR-chpgu-3D 2014). دو كيوتى chpgu-3D براى طول ريشه بحه و وزن خشك ريشه ترتيب در موقعيت r/A ناحيه متفاوت كروموزوم 3D مكانيابى شدند. همجنين روى كروموزوم 4A دو كيوتىال براى تعداد ريشههِه با

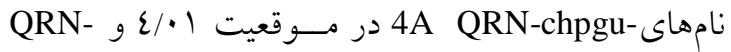
درر موقعيت ع./rhpgu-4A خشك ساقه جֶه يك كيوتى ال (QSDW-chpgu-4A) در

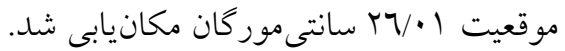

سانتى متر بلدست آمد. براى اين صفت مقدار بدست آمده براى والد كاز (1/ع سانتىمتر) بيشتر از مانتنا (10 (10 سانتى متر) بود و ير اكندگى مقادير افراد جمعيت در بين دو والد و يا بيشتر و كمتر از دو والد صورت گرفت. براى طول ريشهجه نيز نتيجه مشابهى بلدست آمد، بطوريكه حداقل طول ريشهجه براى جمعيت مورد بررسى 1/0 سانتى متر از هر دو والد كمتر بود و والد كاز با عس/• سانتى متر مقدارى برابر با ميانخين جمعيت داشت. براى

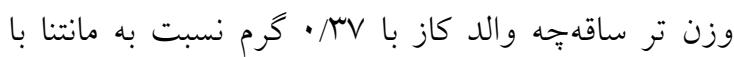
^ץ/ • گرم مقدار بيشترى را نشان داد و براى نسبت وزن خشك ساقه جֶه به ريشه جِه هر دو والد نسبت به لاينهاى مورد بررسى ميانكين كمترى نشان دادند. تفكيك مشاهده شده بر اساس مقادير فنوتييى اندازهيرى شده براى تعداد ريشهإه كه صفت مهم براى گياه بوده و نقش اساسى در زندكى گياه را ايفا مى كند، توزيع نرمال نشان داد. براى اين صفت نيز والد كاز با ع/ع عدد ريشهجهه برتر از مانتنا با ب/ ب عدد ريشهجه بود و ميانكين لاينهاى درون جمعيت در بين دو والد قرار داشت. ميزان وزن خشك بـ

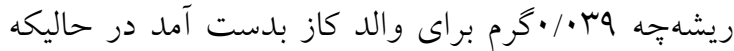
اين مقدار براى والد ديخر (مانتنا) برابر هبr •/ گرم بود كه هر دو والد نسبت به ميانخين جمعيت مقادير كمترى را نشان دادند كه نشان دهنده تفرق متجاوز زنها در جمعيت مىباشد. با توجه به اينكه در جمعيت اينبردلاين نوتركيب طى نسلهاى متوالى غالبيت بين زنها و لينكازها تقريبا شكسته شده و از بين مىروند، مىتوان كفت كه تفرق

جدول. ا- تجزيه واريانس براى صفات مرتبط با ساقهجه و ريشه هُه (مقادير ارائه شده ميانخين مربعات صفات مىباشند) Table 2- ANOVA for stemlet and rootlet related traits (The presented values are mean square)

\begin{tabular}{|c|c|c|c|c|c|c|c|c|c|c|}
\hline $\begin{array}{l}\text { منابع تغييرات } \\
\text { S.O.V }\end{array}$ & $\begin{array}{l}\text { درادى دادى } \\
\text { DF }\end{array}$ & $\begin{array}{l}\text { ريشهاد } \\
\text { Rootlet } \\
\text { number }\end{array}$ & $\begin{array}{c}\text { طول ريشه } \\
\text { Rootlet } \\
\text { length }\end{array}$ & $\begin{array}{c}\text { طول ساقه } \\
\text { stemlet } \\
\text { Length }\end{array}$ & 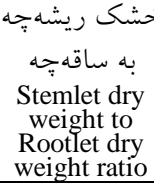 & 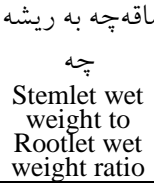 & 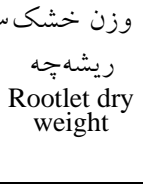 & وزن خشاقه & $\begin{array}{c}\text { وزن تر ساقه } \\
\text { Stemlet wet } \\
\text { weight }\end{array}$ & 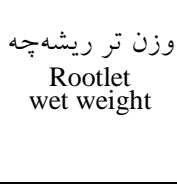 \\
\hline $\begin{array}{l}ل ا ن \\
\text { line }\end{array}$ & 143 & $0.37 * *$ & $21.86 * *$ & $14.58^{* * *}$ & $0.68^{* * *}$ & $0.122^{* * *}$ & $0.0095 * *$ & $0032^{* * *}$ & 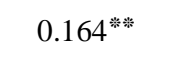 & $0.276^{* *}$ \\
\hline $\begin{array}{l}\text { Uا } \\
\text { Error }\end{array}$ & 288 & 0.048 & 1.15 & 2.05 & 0.047 & 0.016 & 0.0005 & 0.00057 & 0.018 & 0.022 \\
\hline 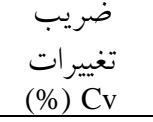 & - & 5.56 & 10.08 & 10.7 & 17.9 & 12.6 & 14.8 & 14.94 & 11.5 & 12.8 \\
\hline
\end{tabular}


4-(CH.1B1)

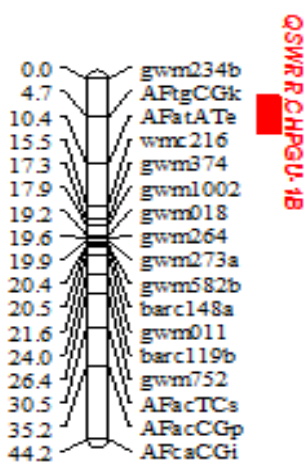

16-(CH.3B2)

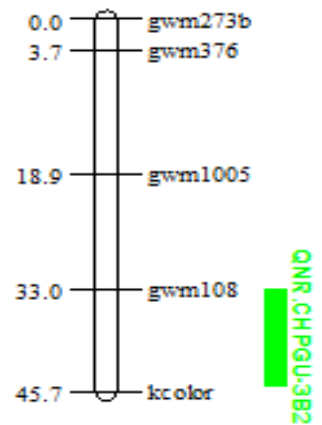

22-(CH.4B)
12-(CH.2B)

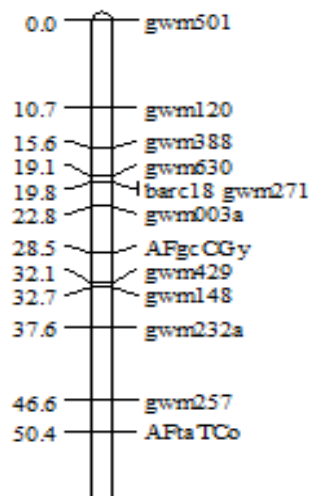

19-(CH.3D 2)

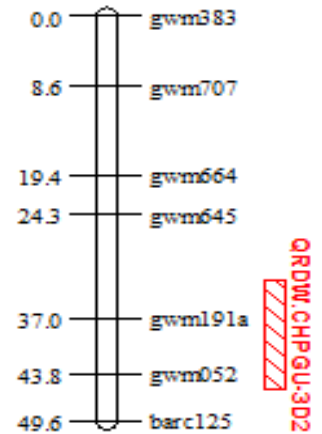

\section{0-(CH.6B)}

13-(CH.2D1)

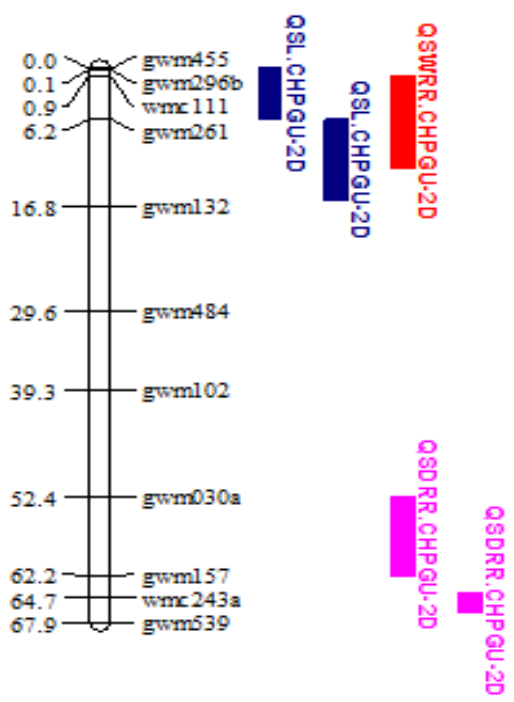

21-(CH.4A2)

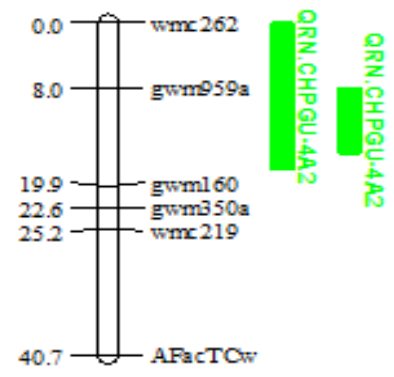

23-(CH.4D)
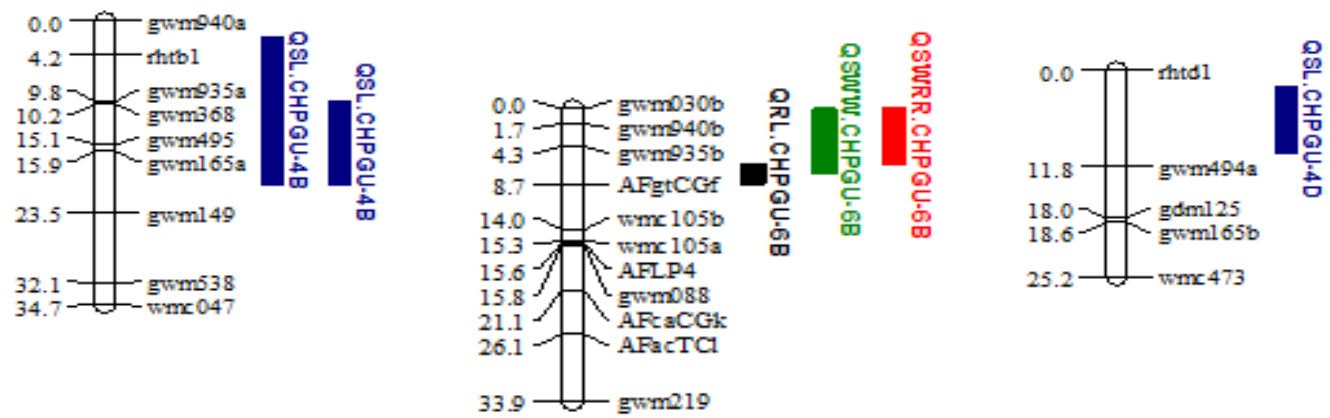

24-(CH.5A1)

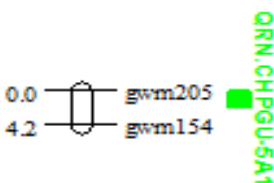

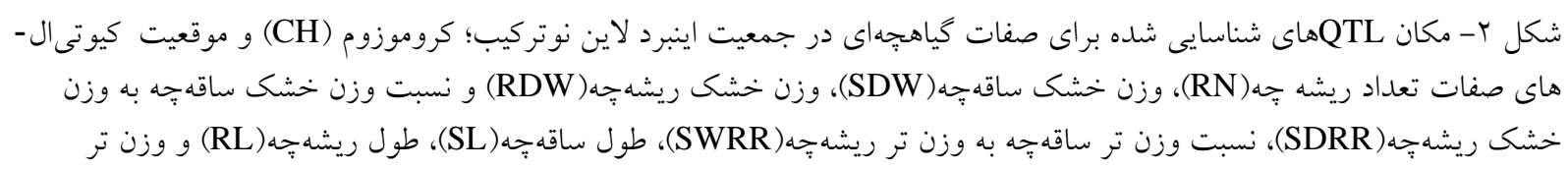

ساقه

Figure 2. The identified QTLs location for seedling stage traits in RIL population; chromosome (CH) and QTLs position for rootlet number (RN), Stemlet dry weight (SDW), Rootlet dry weight (RDW), Stemlet dry weight to rootlet dry weight ratio (SDRR), Stemlet wet weight to rootlet wet weight ratio (SWRR), Stemlet Length (SL), Rootlet length (RL) and Stemlet wet weight (SWW). 
مكانيابى شد و تنها r·•• سانتىورگان با نشانگر Gwm707 فاصله داشت و داراى اثر افزايشى مثبت بوده و

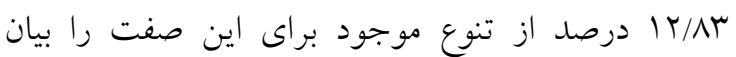
نمود. اين كيوتىال از والد كاز به ارث رسيد.

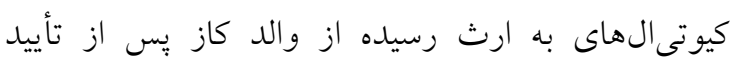

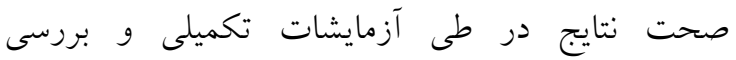

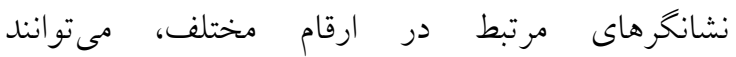

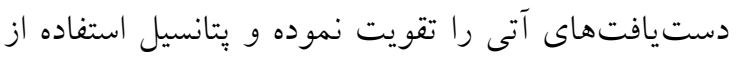
كيوتىالها در برنامه انتخاب به كمى نشانكر جهت اصلاح كندم در مرحله كياهجه را افزايش دهند. وجود كيوتى الهاى مهم به ارث رسيده از والد متحمل به كرما

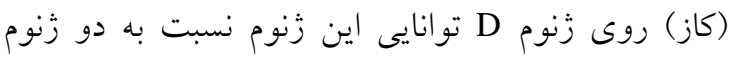
ديخر در انتقال مجدد مواد، ايجاد ريشه و ساقه قوى را نمايان مىسازد. علاوه بر اين، نتايج نشان داد كه مناطق زنتيكى كنترل كننده صفات مهم مربوط به مراحل كياهجهاى كندم در اين آزمايش از والد كاز به ارث رسيدند و اين مناطق زُنتيكى بيشتر روى دو زنوم B و D D

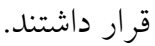
با توجه به اينكه جوانهزنى سريع و داشتن ويزگكىهاى مطلوب در توليد ريشهجه و ساقهجه از عوامل اصلى

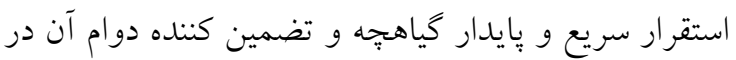

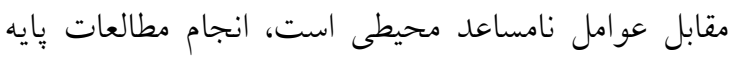
مانند مطالعه اخير در شناسايى كيوتى الهاى كنترل كنّلده صفات مرتبط با ريشهجه و ساقهجه مىتواند در بيشبرد

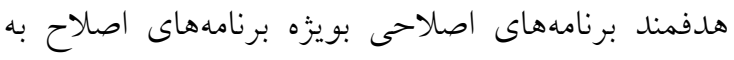
كمى نشانكر ها مفيد واقع شود.

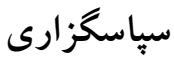
از يروفسور يتريك برن استاد دانشگاه ايالتى كلرادوى

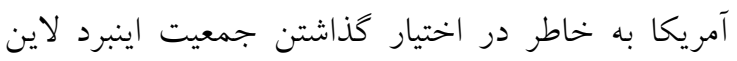

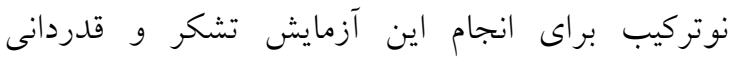
مى كردد.
هر سه كيوتىال كوجى اثر بوده و ميزان تنوع ناجيزى براى صفات ياد شده را بيان كردند. باى و همكاران ( Bai א et al., 2013 كيوتى الها مىتوانند براى صفات ريشه و ساقه به صورت

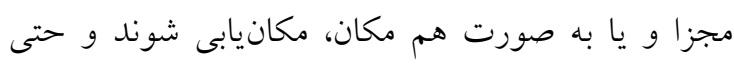
مىتوانند با صفات مرتبط با مراحل بلوغ كياه همجيون وزن هزار دانه و ارتفاع هممكان باشند. در صورت قرار داشتن كيوتىالها براى صفات مختلف بر روى يك

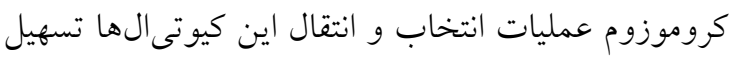
خواهد شد. كيوتىال IT/NV ، QRN-chpgu-5A درصد از تنوع فنوتيى براى تعداد ريشهجه را بيان كرد و در

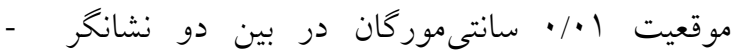
وقرار داشت. در يك آزمايش مشابه gwm205 gwm154 كريستوفر و همكاران (Christopher et al., 2013) نيز كيوتىالهاى تعداد ريشهجه را روى كروموزوم كزارش كردند. ليو و همكاران (Liu et al., 2013) نيز نشان دادند كه برخى كيوتىالهاى مربوط به تعداد ريشه-

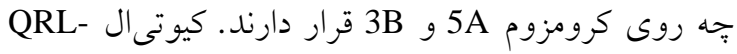

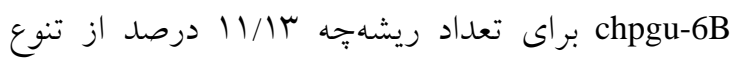

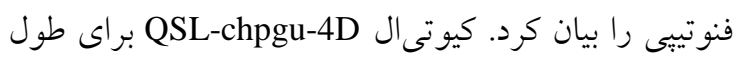

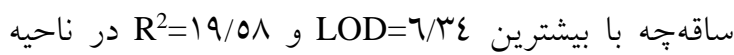

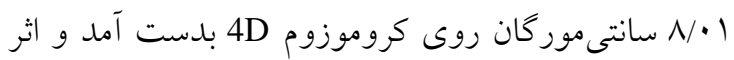
افزايشى مثبت (1/T90) روى ساقه نشان داد. نشانگر gwm494a

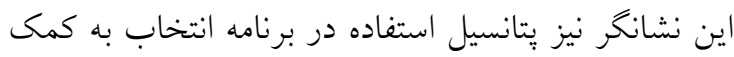
نشانكر را داراست. در مطالعات قبلى اليس و همكاران نيز زنهاى پاكوتاهى را بر روى (Ellis et al., 2002) كروموزوم 4D كزارش كردند كه مىتواند نشان از اهميت

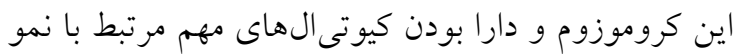
و مورفولوزى ساقه باشد. كيوتىال QSDRR-chpgu-6B براى نسبت وزن خشك ساقهجه به ريشهاهه روى كروموزوم 3D و در موقعيت N/OV سانتى موركان 
جدول r - كيوتى ال هاى شناسايى شده براى صفات مرتبط با ساقه بحه و ريشه

Table 2. Detected QTLs for stemlet and rootlet related traits

\begin{tabular}{|c|c|c|c|c|c|c|c|}
\hline ت & $\begin{array}{l}\text { نام كيو.تى ال } \\
\text { QTL name }\end{array}$ & $\begin{array}{l}\text { جايگاه } \\
\text { Positio } \\
\text { n }\end{array}$ & $\begin{array}{c}\text { شماره كروموزوم } \\
\text { Chromosome } \\
\text { number }\end{array}$ & LOD & نشانكرهاى مجاور & 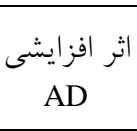 & بريب تبيي \\
\hline & QSL-chpgu-4D & 8.01 & $4 \mathrm{D}$ & 6.34 & rhtd1 - gwm494a (3.82)* & 1.295 & 0.1958 \\
\hline 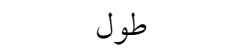 & QSL-chpgu-4B & 10.23 & $4 \mathrm{~B}$ & 2.34 & gwm368 - gwm495 (0.01) & -0.6674 & 0.0543 \\
\hline ساقه جه & QSL-chpgu-4B & 8.18 & $4 \mathrm{~B}$ & 2.33 & rhtb1 - gwm935a (1.57) & -0.6927 & 0.0590 \\
\hline $\begin{array}{l}\text { Stemlet } \\
\text { Length }\end{array}$ & QSL-chpgu-2D & 12.19 & $2 \mathrm{D}$ & 2.33 & gwm261 - gwm132(4.6) & -0.7659 & 0.0764 \\
\hline & QSL-chpgu-2D & 4.91 & $2 \mathrm{D}$ & 2.12 & wmc111 - gwm261 (1.28) & -0.6820 & 0.0605 \\
\hline طول ريشهحه & QRL-chpgu-6B & 8.26 & $6 \mathrm{~B}$ & 3.58 & gwm935b - AfgtCGf(0.402) & 0.8004 & 0.1113 \\
\hline Rootlet length & QRL-chpgu-3D & 3.82 & $3 \mathrm{D}$ & 2.35 & $\begin{array}{c}\text { AfgcCGb - wmc011a } \\
(0.005)\end{array}$ & -0.5145 & 0.063 \\
\hline & QRN-chpgu-3B & 43.03 & $3 \mathrm{~B}$ & 2.42 & gwm108 - kcolor(2.43) & 0.1154 & 0.0775 \\
\hline تعداد ريشه ֶجه & QRN-chpgu-4A & 4.01 & $4 \mathrm{~A}$ & 2.60 & wmc262 - gwm959a (4.01) & -0.9411 & 0.0827 \\
\hline Rootlet number & $\begin{array}{l}\text { QRN-chpgu-4A } \\
\text { QRN-chpgu-5A }\end{array}$ & $\begin{array}{c}12.04 \\
0.01\end{array}$ & $\begin{array}{l}4 \mathrm{~A} \\
5 \mathrm{~A}\end{array}$ & $\begin{array}{l}2.33 \\
3.23\end{array}$ & $\begin{array}{c}\text { gwm959a - gwm160(4.012) } \\
\text { gwm205 - gwm154(0.01) }\end{array}$ & $\begin{array}{l}-0.1165 \\
-0.1476\end{array}$ & $\begin{array}{l}0.0785 \\
0.1277\end{array}$ \\
\hline وزن خشك & & & & & & & \\
\hline 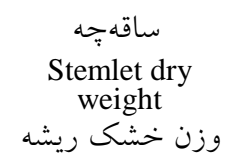 & QSDW-chpgu-4A & 26.01 & $4 \mathrm{~A}$ & 2.61 & gwm601- gwm397a (4.09) & -0.0065 & 0.0747 \\
\hline $\begin{array}{c}\text { Reotlet dry } \\
\text { weight }\end{array}$ & QRDW-chpgu-3D & 38.96 & $3 \mathrm{D}$ & 3 & gwm191a - gwm052(2) & -0.0064 & 0.0986 \\
\hline سبت وزنه به ريشه & $\begin{array}{l}\text { QSDRR-chpgu-2D } \\
\text { QSDRR-chpgu-2D }\end{array}$ & $\begin{array}{l}60.38 \\
66.72\end{array}$ & $\begin{array}{l}2 \mathrm{D} \\
2 \mathrm{D}\end{array}$ & $\begin{array}{l}2.06 \\
2.86\end{array}$ & $\begin{array}{c}\text { gwm030a - gwm157(1.8) } \\
\text { wmc243a - gwm539(1.08) }\end{array}$ & $\begin{array}{l}-0.0976 \\
-0.1082\end{array}$ & $\begin{array}{l}0.0889 \\
0.1107\end{array}$ \\
\hline $\begin{array}{c}\text { Stemlet dry } \\
\text { weight to rootlet } \\
\text { dry weight ratio }\end{array}$ & QSDRR-chpgu-3D & 8.57 & $3 \mathrm{D}$ & 4.2 & Gwm707 - gwm664(0.02) & 0.1173 & 0.1283 \\
\hline وزن تر ساقه جه & QSWW-chpgu-2B & 65.81 & $2 \mathrm{~B}$ & 3.4 & wmc025 - wmc $243 b(0.01)$ & -0.1332 & 0.0927 \\
\hline $\begin{array}{l}\text { Stemlet wet } \\
\text { weight }\end{array}$ & QSWW-chpgu-6B & 1.7 & $6 \mathrm{~B}$ & 2.36 & gwm940b - gwm935b(0.02) & -0.1111 & 0.0672 \\
\hline نسبت وزن به ريشه ساقه & $\begin{array}{l}\text { QSWRR-chpgu-1B } \\
\text { QSWRR-chpgu-2D }\end{array}$ & $\begin{array}{l}2.58 \\
6.19\end{array}$ & $\begin{array}{l}1 \mathrm{~B} \\
2 \mathrm{D}\end{array}$ & $\begin{array}{l}2.58 \\
2.04\end{array}$ & $\begin{array}{l}\text { AftgCGk - AfatATe(0.02) } \\
\text { gwm261 - gwm132(0.02) }\end{array}$ & $\begin{array}{c}0.1056 \\
-0.0882\end{array}$ & $\begin{array}{l}0.0810 \\
0.0536\end{array}$ \\
\hline $\begin{array}{c}\text { Stemlet wet } \\
\text { weight to rootlet } \\
\text { wet weight ratio }\end{array}$ & QSWRR-chpgu-6B & 4.26 & $6 \mathrm{~B}$ & 2.65 & gwm935b - AfgtCGf(0.01) & -0.0851 & 0.0511 \\
\hline 00 & ل - مانخر مجاو, & 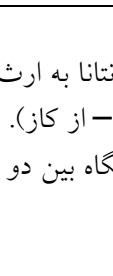 & رَتيب از والد كاز يا & 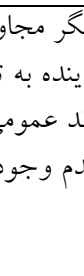 & 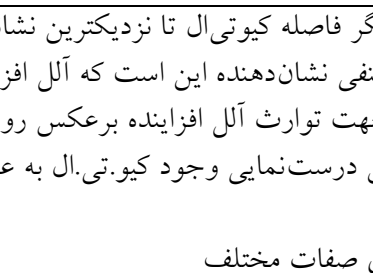 & 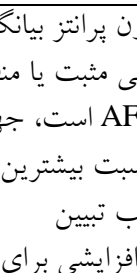 & 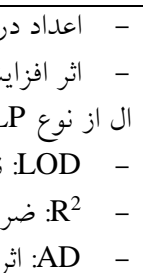 \\
\hline
\end{tabular}

- Numbers in parenthesis indicate interval to nearest flanking marker

- Negative or positive additive effect showed the heredity of alleles from Kaz or Montana, respectively. When the flanking marker of QTLs are AFLP, the sign of heredity of additive allele was inverse to common process (+from Montana and - from Kaz).

- LOD: Logarithmic of odds

R2: Coefficient of determination

- $\quad$ AD: Additive effect for different treats

\section{References}

Araki, H. and Iijima, M. (2001). Deep rooting in winter wheat: rooting nodes of deep roots in two cultivars with deep and shallow root systems. Plant Production Science, 4: 215-219.

Bai, C., Liang, Y. and Hawkesford, M.J. (2013). Identification of QTLs associated with seedling root traits and their correlation with plant height in wheat. Journal of Experimental Botany, 6:17451753.

Bhar, S., Balyan, H.S. and Gupta, P.K. (2014). Quantitative trait loci analysis for some root traits in bread wheat (triticum aestivum L.). International Journal of Agricultural Sciences, 7: 214-221. 
Christopher, J., Jennings, R., Jones, S., Fletcher, S., Borrell, A. M. A., Jordan, D., Mace, E. and Hammer, G. (2013). QTL for root angle and number in a population developed from bread wheats (Triticum aestivum) with contrasting adaptation to water-limited environments. Theoretical and Applied Genetics, 126:1563-1574.

Dorlodot, S.D., Forester, B., Pages, L., Price, A., Tuberosa, R. and Draye, X. (2007). Root system architecture: opportunities and constructions for genetic improvement crops. Trends in Plant Science, 10: 474-481.

Ellis, M.H., Spielmeyer, W., Gale, K.R., Rebetzke, G.J. and Richards, R.A. (2002). Perfect's markers for the Rht B1b and Rht D1b dwarfing genes in wheat. Theoretical and Applied Genetics, 105: $1038-1042$.

Gregory, P. (2006). Roots and the architecture of root systems. In: Plant roots: growth, activity and interactions with soils. Oxford, Blackwell Publishing, UK.

Gupta, P.K., Balyan, H.S. and Varshney, R.K. (2010). Quantitative genetics and plant genomics: an overview. Molecular Breeding, 26: 133-134.

Hamada, A., Nitta, M., Nasuda, S., Kato, K., Fujita, M. and Matsunaka, H. (2012). Novel QTLs for growth angle of seminal roots in wheat (Triticum aestivum L.). Plant and Soil, 354: 395-405.

Ibrahim, A., and Quick, J.S. (2001). Genetic control of High temperature tolerance in wheat as measured by membrane thermal. Crop Science, 41:1405-7.

Landjeva, S., Neumann, K., Lohwasser, U. and Borner, A. (2008). Molecular mapping of genomic regions associated with wheat seedling growth under osmotic stress. Biologia Plantarum, 52: 259266.

Liu, X.L., Li, R.Z., Chang, X. P. and Jing, R.L. (2013). Mapping QTLs for seedling root traits in a doubled haploid wheat population under different water regimes. Euphytica, 189: 51-66.

Lu, C.X., Guo, J.Q., Wang, Y., Leng, J.T., Yang, G.M, Hou, W.S., Wu, C.X. and Han, T.F. (2010). Identification, inheritance analysis, and QTL mapping of root and shoot traits in soybean variety PI471938 with tolerance to wilting. Acta Agronomica Sinica, 36: 1476-1483.

Manske, G.G.B. and Vlek, P.L.G. (2002). Root architecture-wheat as a model plant. In: Waisel Y., Eshel A., Kafkafi, U. (Eds). Plant roots: the hidden half. Marcel Dekker Inc., New York, USA.

Modarresi, M. (2009). QTL Analysis for yield, yield component and thermal tolerance in wheat (Triticum aestivum). Ph.D. Thesis. Tehran University, Tehran, Iran.

Mohammadi, V., Qannadha, M.R., Zali, A.A., and Yazdi-Samadi, B. (2004). Effect of post anthesis heat stress on head traits of wheat. International Journal of Agriculture and Biology, $\mathbf{6}$ : 42-44.

Poorsahrigh, S.G., Mohammadi, S.A. and Sadeghzadeh, B. (2014). Identification of genomic origins controlling iron concentration and content in shoot of barley in $\mathrm{A} \times \mathrm{B}$ doubled hoploid mapping population. Journal of Plant Genetic Researches, 1 (1):1-12.

Rong, Z., Chen, H., Wang, X., Wu, B., Chen, S., Zhang, X., Wu, X., Yang, Z., Qiu, D., Jiang, M. and Zhou, X. (2011). Analysis of QTLs for root traits at seedling stage in soybean. Acta Agronomica Sinica, 7: 1151-1158.

Zhou, R., Chen, H.F., Wang, X.Z., Wu, B.D., Chen, S.L., Zhang, X.J., Wu, X.J., Yang, Z.L., Qiu, D.Z., Jiang, M.L. and Zhou, X.-A. (2011). Analysis of QTLs for Root Traits at Seedling Stage in Soybean. Acta Agronomica Sinica, 37: 1151-1158.

Sanguinet, M.C., Maccaferr, L.S., Cornet, M., Rotondo, S.F., Chiar, T. and Tuberosa, R. (2007). Genetic dissection of seminal root architecture in elite durum wheat germplasm. Annals of Applied Biology, 151: 291-305.

Sun, G.Y., He, Y., Zhang, R.H. and Zhang, D.P. (1996). Studies on growth and activities of soybean root. Soybean Science, 15: 317-321.

Voorrips, R.E. (2002). MapChart: software for the graphical presentation of linkage maps and QTLs. Journal of Heredity, 93:77-78.

Wang, S.C., Basten, C.J. and Zeng, Z.B. (2005). Windows QTL cartographer 2.5, user manual. Department of Statistics, North Carolina State University, Raleigh, N.C., USA.

Yang, M., Ding, G., Shi, L., Feng, J., Xu, F. and Meng, J. (2010). Quantitative trait loci for root morphology in response to low phosphorus stress in Brassica napus. Theoretical and Applied Genetics, 121: 181-193.

Zhang, H., Cui, F., Wang, L., Li, J., Ding, A., Zhao, C., Bao, Y., Yang, Q. and Wang, H. (2013). Conditional and unconditional QTL mapping of drought-tolerance-related traits of wheat seedling using two related RIL populations. Journal of Genetics, 92: 213-231.

Zhou, X.G., Jing, R.L., Hao, Z.F., Chang, X.P. and Zhang. Z.B. (2005). Mapping QTL for seedling root traits in common wheat. Sciatica Agricola, 38: 1951-1957.

Zhu, J., Kaeppler, S.M. and Lynch, J.P. (2005). Mapping of QTL controlling root hair length in maize (Zea mays L.) under phosphorus deficiency. Plant and Soil, 270: 299-310. 


\title{
QTLs Associated with Stemlet and Rootlet Growth in the Early Stages of Germination of Wheat
}

\section{Mohsen Barajehfard ${ }^{1}$, Mohammad Reza Siahpoosh ${ }^{2, *}$ and Mohammad Modarresi ${ }^{3}$}

1. M.Sc. Student, Department of Agronomy and Plant Breeding, Shahid Chamran University of Ahvaz, Ahvaz, Iran

2- Assistant Professor, Department of Agronomy and Plant Breeding, Shahid Chamran University of Ahvaz, Ahvaz, Iran

3- Assistant Professor, Department of Agronomy and Plant Breeding, Persian Gulf University, Bushehr, Iran

(Received: September 11, 2016 - Accepted: December 28, 2016)

\begin{abstract}
In order to identify QTLs associated with stemlet and rootlet growth in the early stages of germination of wheat, 144 recombinant inbred lines derived from the cross of Kaz and Mantana were evaluated in a completely randomized design. The linkage map using composite interval by 234 microsatellite (SSR) primers and 267 AFLP loci have been already prepared in this population which covered 20 chromosomes of wheat. For root length, 1, 2 and 2 QTLs were located on 4D, 4B and 2D chromosomes, respectively. Two QTLs of rootlet length was located on 6B and 3D chromosomes. The QTLs of rootlet number were identified on 4A, 5A and 3B chromosomes. For each of stemlet dry weight (SDW) and rootlet dry weight (RDW) traits only one QTL identified on 4A and 3D chromosomes, respectively. Overall, for SDW to RDW ratio on 2D and 3D chromosomes, three QTLs were located. The QTLs of stemlet wet weight (SWW) were detected on 6B and 2B chromosomes. On 1B, 2D and 6B chromosoms, three QTLs were recognized for SWW to RWW ratio. For all traits, the range of LOD $=2.04-6.34$ and $\mathrm{R} 2=5.11-19.58$ were calculated. The highest amount of LOD and R2 (5.11 and 19.58, respectively) were obtained for rootlet length QTL (QSL-chpgu-4D). The least distance to the nearest adjacent marker (AFgcCGb marker) was 0.005 Centi-Morgan which belonged to rootlet length QTL (QRL-chpgu-3D) on 3D chromosome.
\end{abstract}

Keywords: Stemlet, QTL, Seedling, Wheat, Rootlet

\footnotetext{
${ }^{*}$ Corresponding Author, E-mail: Siahpoosh@scu.ac.ir
} 